\title{
QUALITATIVE ANALYSIS FOR THE DIAGNOSIS OF THE LEAN CONSTRUCTION IMPLEMENTATION
}

\author{
Tatiana G. do Amaral ${ }^{1}$, Letícia G. Oka ${ }^{2}$, Carlos A. B. de Camargo Filho ${ }^{3}$, and José \\ P. Barros Neto ${ }^{4}$
}

\begin{abstract}
The paper presents an analysis of the implementation of Lean Construction in the center of Brazil, and an evaluation of the potentialities that each calculation method provides in the diagnosis. The Lean Construction Assessment Tool (LCAT) was used in this research to make critical inferences about the Lean implementation stage in six construction companies in Goiânia, Brazil. Based on the data obtained, the Lean Score was calculated using arithmetic averages, weighted averages and averages based on the Fuzzy Inference System. Based on this analysis, an evaluation of each LCAT criteria was inferred, and its influence on the company's lean score was determined. The advantages and disadvantages of the lean construction implementation process were also evidenced. The measurements obtained presented small variations, such as speed of obtaining the data, interference of other variables in the process, and analysis of specialists. Nevertheless, it was possible to draw conclusions about the different potentialities of the use of each one.
\end{abstract}

\section{KEYWORDS}

Lean construction; evaluation methods; implementation stage; mathematical results.

\section{INTRODUCTION}

The current Brazilian construction industry has undergone many changes (FGV/IBRE, 2017). As a result, new systems, methodologies, and tools are needed that will ensure improvements, with less use of resources and without losing the quality and efficiency of the process. In this context, Lean Construction has become a popular concept.

Along with the advent of the philosophy of production linked to construction, managerial changes are taking place, and the market is beginning to perceive changes in relation to new practices, seeking technological and managerial improvement. As part of these changes, there is a growing search for knowledge related to Lean concepts (Silva et al., 2014).

Professor, Environmental and Civil Engineering. Dept., Universidade Federal de Goiás, Brazil, +55 62 981680902, tatiana_amaral@ hotmail.com

2 Civil Engineer, Projects Dept, Dennis Group, Brazil, +55 62 983319111, letyoka@ gmail.com

3 Civil Engineer, Dusol Engenharia Sustentável, Brazil, +55 62 984228992, carlos_bouhid@ @otmail.com

4 Full Professor, Structural and Civil Construction. Dept., Universidade Federal do Ceará, Brazil, +55 85 999691871, barrosneto@gercon.ufc.br 
The use of lean construction practices has gradually spread throughout the construction industry. Mechanisms are therefore needed to evaluate their use, making it easier to identify the advantages and disadvantages of the Lean Construction implementation process (ETGES et al., 2013).

An evaluation method is used to measure the degree of Lean implementation. However, measuring the degree of Lean implementation is complex, due to (a) the inherent multidimensional concept of "lean"; (b) the unavailability of information on manufacturing practices that could be used for benchmarking when evaluating the degree of leanness; and (c) the subjectivity of human judgment on Lean practices, such as lack of precision and pre-judgment, depending on the evaluator's knowledge and experience (Susilawati et al., 2014).

Silva (2011) presents an evaluation checklist of the degree of lean implementation in construction companies, based on Fuzzy logic.

Carvalho (2008) comments that there are still scenarios in which the company does not obtain satisfactory results, such that the systems begin to operate with low efficiency, leading the company to return to the traditional system because in these cases, the innovation did not provide the expected benefits.

Miron et al. (2016) use a logical structural model to synthesize the literature on the subject, and establish an initial proposal for evaluating continuous improvement programs in the context of lean construction.

The main aim of this study is analyze the application of the Lean diagnosis tool, considering the potential of each average used. It also evaluates each criteria of the LCAT, and determines how it influences the lean index of companies.

Specifically, the application of the evaluation method created by Silva (2011) and improved by Camargo Filho (2017) will be detailed through the application of the developed questionnaire form, in order to demonstrate an evolution from the methods already applied by other authors.

The main contribution of the research is that it provides a better understanding of the metrics that can be used to evaluate the level of implementation of lean construction practices, and that are appropriate for the organizational context of Brazilian companies, using, for this purpose, the evaluation tool proposed by Camargo Filho (2017).

\section{LEAN CONSTRUCTION AND EVALUATION QUESTIONNAIRES}

Salem et al. (2006) developed a lean evaluation checklist that presented six categories: Last planner, increased visualization, preliminary studies, huddle meetings, the $5 \mathrm{Ss}$, and fail safe for quality. The results were rated as: none $(\mathrm{N})$, very low $(\mathrm{VL})$, low $(\mathrm{L})$, moderate $(\mathrm{M})$, high $(\mathrm{H})$, or very high $(\mathrm{VH})$.

Carvalho (2008) produced a questionnaire that evaluated five components: board of directors, engineering, workers, suppliers and projectors. Unlike other authors, Carvalho (2008) consulted clients about their perceptions regarding lean principles at the company. Four levels of implementation were assigned to each topic. A final score was then attributed, based on the percentage of fulfilment of these principles and characteristics.

Etges (2012) developed a protocol for auditing the use of Lean Construction practices, taking into consideration four fundamental stages: a literature review of IGLC procedures 
(1993 to 2010) and the main keywords of the papers retrieved, definition of sources of evidence to evaluate the use of each category, definition of weights attributed to each practice by six lean construction specialists, and the application of the protocol by a civil construction company. One hundred and three practices were established, and the construction company's performance in each category was presented as a percentage.

\section{FUZZY INFERENCE SYSTEM}

According to Susilawati et al., (2014), the Fuzzy method is a mathematical theory that enables ambiguities and imprecisions to be modeled by means of Fuzzy sets. The decision methods based on this logic can help to establish the relative importance raking in the evaluation of the performance systems of measuring.

Silva (2011) elaborated an innovative work in the Fuzzy Inference System application for diagnosis and monitoring of the lean construction philosophy in civil construction companies. Through checklists and subsequent weighting of the variables using Fuzzy, he sought to reduce the uncertainties in the evaluation methods used. Silva et al (2014) present the application of these checklists.

\section{FORM APPLIED IN THE RESEARCH}

The main theoretical underpinning of the questionnaire developed by Camargo Filho (2017) is the studies of Womack and Jones (1996). Also created with the aim of evaluating the level of implementation of Lean Construction practices in construction companies, that questionnaire has undergone three revisions, before becoming consolidated in the final version.

Camargo Filho (2017) conducted a pilot application in seventeen companies, with the aim of validating the questionnaire. However, satisfactory results were not obtained in relation to its applicability; it was long and tiring, and not very effective, due to the organization of its criteria, as a large number of them only addressed practices linked directly to quality management, which could compromise the clarity of the results obtained, and the real lean diagnosis of the company.

The author therefore attempted to simplify the questionnaire, making it more precise and direct, and avoiding repetition and rework through the implementation of a logical application sequence. It also removed items that were given as compulsory or related to legislations in force related to health and safety, sustainability and quality, focusing on specific items characteristic of Lean Construction.

The Fuzzy inference system was used, together with the final version of the form, to obtain the diagnostic of companies. A system comprising 81 inference rules was proposed, with four input variables and one output variable.

Camargo Filho (2017) initially elaborated version 2.0 of the questionnaire, which evaluated 98 practices distributed in 10 categories: Quality Management, Cost Control, Safety at Work, Visual Management, Continuous Improvement, Information Technology, Human Resources, Logistics and Supply Chain Management, Project Management and Product Development, and Planning Production and Control. A Fuzzy Inference System was proposed with four input variables and one output variable, with a total of 84 inference rules. 
The final version of the questionnaire (version 3.0) is shown in Figure 1. It has 4 categories: Quality Management, Supply Chain Management, Planning Production and Control, and Project Management. Among these categories, there are 84 lean practices, in which the final percentage of fulfilment of the criteria defines how lean the company is. The levels were distributed across three stages of implementation: initial (level 0), maturation (level 1), and continuous improvement (level 2)

\begin{tabular}{|c|c|c|}
\hline CATEGORY & PREREQUISITE & CRITERIA \\
\hline \multirow{7}{*}{$\begin{array}{l}\text { Quality } \\
\text { Management }\end{array}$} & \multirow{7}{*}{$\begin{array}{l}\text { Certified Quality } \\
\text { Management System }\end{array}$} & Worker training \\
\hline & & Problem Solving \\
\hline & & Internal and External Benchmarking \\
\hline & & Use of Poka-yokes and Technological Innovation \\
\hline & & Performance Evaluation \\
\hline & & Motivational Policies and Worker Satisfaction \\
\hline & & Organization of the workplace and construction site \\
\hline \multirow{7}{*}{$\begin{array}{l}\text { Supply } \\
\text { Chain } \\
\text { Management }\end{array}$} & \multirow{3}{*}{$\begin{array}{l}\text { Defined criteria for } \\
\text { supplier selection }\end{array}$} & Supplier Selection \\
\hline & & Supplier relations \\
\hline & & Buying process \\
\hline & \multirow{4}{*}{$\begin{array}{l}\text { Control of delivery of } \\
\text { materials in } \\
\text { compliance with } \\
\text { specifications and } \\
\text { quality }\end{array}$} & Stock and material storage control \\
\hline & & Physical space control \\
\hline & & Internal distribution of supplies \\
\hline & & Controlling costs in the supply chain \\
\hline \multirow{6}{*}{$\begin{array}{l}\text { Planning } \\
\text { Production } \\
\text { and Control }\end{array}$} & \multirow{2}{*}{$\begin{array}{l}\text { Planning Production } \\
\text { and Control Process } \\
\text { formalized }\end{array}$} & Long-term planning \\
\hline & & Medium-term planning \\
\hline & \multirow{2}{*}{$\begin{array}{l}\text { Transparent long-term } \\
\text { plan }\end{array}$} & Short-term planning \\
\hline & & Value Stream Mapping \\
\hline & \multirow{2}{*}{$\begin{array}{l}\text { General defined } \\
\text { activity stream }\end{array}$} & Production Control \\
\hline & & Cost Control \\
\hline \multirow{4}{*}{$\begin{array}{l}\text { Project } \\
\text { Management }\end{array}$} & \multirow{2}{*}{$\begin{array}{l}\text { Internal department } \\
\text { responsible for project } \\
\text { management }\end{array}$} & Project Development Planning \\
\hline & & Compatibility and validation of projects \\
\hline & \multirow{2}{*}{$\begin{array}{l}\text { Project verification } \\
\text { process regarding } \\
\text { quality and } \\
\text { specifications }\end{array}$} & Identification of the value required by the client \\
\hline & & Identification of problems in projects \\
\hline
\end{tabular}

Figure 1: Camargo Filho Questionnaire (2017).

\section{METHOD}

The research was classified according to its approach, nature, objectives and procedures. In terms of approach, it was classified as quantitative and qualitative, as it analyses the numerical results of the application of the form to evaluate the degree of lean implementation in the six companies evaluated in the city of Goiânia. It is also considered qualitative because it presents meanings, results and theoretical interpretations based on the scores assigned to each category of lean implementation. 


\section{CRITERIA FOR SELECTION OF THE PARTICIPATING COMPANIES}

In the second stage of the research, the participating companies were selected, based on the following criteria: 1) companies operating in the local market; 2) the existence, within the company, of a Quality and/or Environmental Management System; and, 3) interest in participating in academic studies aimed at improving their processes.

\section{ChaRACTERIZATION OF THE COMPANIES}

Data were collected from six construction companies in Goiânia between November and December 2016. The companies were classified as medium to large organizations, with more than ten years in operation.

\section{ApPlication of the CaMargo Filho Questionnaire (2017)}

The questionnaire elaborated by Camargo Filho (2017) was applied in the form of a survey. All the scores attributed to each criteria were collected and recorded, with scores ranging from 0 to 2 ( 0 - the process or tool was not present or in a very early stage of implementation; 1 - the maturation stage; 2 - a tool or process implemented and in continuous improvement).

The application process took around one hour per company, which was spent on analyzing the engineers' responses, attributing scores, and spot-checking some of the items mentioned by the respondents.

The data obtained were drawn up in the form of a table and analyzed in three different ways: arithmetic average, weighted averages calculated from the expert analyses of lean construction, establishing degrees of importance for each criteria, and weighting of the results using the Matlab software.

\section{Data Processing}

The arithmetic average was determined using Microsoft Excel, generating an average percentage of fulfilment for each category, with each category having between 4 and 7 criteria. Thus, the percentage of fulfilment for each category is calculated as the average of the scores for the criteria, in relation to the total fulfilment of the criteria.

The weights to be used to calculate the weighted averages were obtained from the analysis of six specialists in the area of Production Management - Lean Construction in relation to the weight attributed for each of the practices in the Lean diagnosis of a company. (0 - initial phase; 1 - maturation phase; 2 - continuous improvement phase). The aspects analyzed were: importance (essential, very important, not important and irrelevant), complexity (complex, intermediate, or basic), time of implementation of practices (initial phase, maturation phase or continuous improvement phase) and ideal time of implementation of lean construction (starting in the first year of implementation and going up to the fifth year of the process).

The average scores attributed by the experts will be used as a weighting to determine the percentages of fulfilment. Table 1 shows an example of how this weighting was presented for the variable "implementation time" and in Table 2 we can see the factors corresponding to this weighting. 
Table 1: Weightings established for the variable "Implementation Time" according to specialists.

\begin{tabular}{|c|c|c|c|c|c|c|c|c|}
\hline \multicolumn{9}{|c|}{ IMPLEMENTATION TIME BY SPECIALISTS } \\
\hline 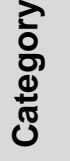 & $\frac{\pi}{\frac{\pi}{2}}$ & ڤ & S1 & S2 & S3 & S4 & S5 & S6 \\
\hline \multirow{4}{*}{ 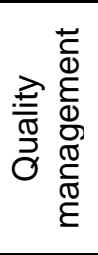 } & \multirow{4}{*}{1} & 1.1 & initial & initial & initial & initial & initial & initial \\
\hline & & 1.2 & maturation & initial & initial & initial & maturation & initial \\
\hline & & 1.3 & $\begin{array}{l}\text { continuous } \\
\text { improvement }\end{array}$ & maturation & $\begin{array}{l}\text { maturati } \\
\text { on }\end{array}$ & $\begin{array}{l}\text { maturati } \\
\text { on }\end{array}$ & maturation & initial \\
\hline & & 1.4 & $\begin{array}{l}\text { continuous } \\
\text { improvement }\end{array}$ & $\begin{array}{l}\text { continuous } \\
\text { improvement }\end{array}$ & $\begin{array}{l}\text { maturati } \\
\text { on }\end{array}$ & $\begin{array}{l}\text { maturati } \\
\text { on }\end{array}$ & $\begin{array}{l}\text { continuous } \\
\text { improvement }\end{array}$ & initial \\
\hline
\end{tabular}

Table 2: Weightings assigned by each specialist (S1, S2, S3, S4, S5, S6).

\begin{tabular}{|c|c|c|c|c|c|c|c|c|c|}
\hline \multicolumn{10}{|c|}{ Weighting factors } \\
\hline Category & Criteria & $\begin{array}{c}\text { Sub- } \\
\text { Criteria }\end{array}$ & S1 & S2 & S3 & S4 & S5 & S6 & $\begin{array}{c}\text { Average of } \\
\text { factors }\end{array}$ \\
\hline \multirow[t]{4}{*}{ Quality management } & 1 & 1.1 & 0 & 0 & 0 & 0 & 0 & 0 & 0.00 \\
\hline & & 1.2 & 1 & 0 & 0 & 0 & 1 & 0 & 0.33 \\
\hline & & 1.3 & 2 & 1 & 1 & 1 & 1 & 0 & 1.00 \\
\hline & & 1.4 & 2 & 2 & 1 & 1 & 2 & 0 & 1.33 \\
\hline
\end{tabular}

Based on the three results; arithmetic average, expert-weighted averages and the averages obtained from the Fuzzy Inference System, it will be possible to produce bar graphs to improve the analyses and their potential results. The objective is not to compare the averages, but to evaluate the potential of the use of each one.

\section{RESULTS AND DISCUSSIONS}

Based on the application of the LCAT tool in the companies, the Lean Score of each company was obtained, i.e. the degree of implementation of the lean construction (Very Low: 0 - 20\%; Low: 20\% - 40\%; Medium: 40\% - 60\%; High: 60\% - 80\%; Very High: 80\% $-100 \%)$.

Nine researchers were responsible for all the applications, but for three companies, it was decided to use cross-application, i.e. two different agents applied the form in the same company for Fuzzy analysis. Companies A, B and C were chosen; two that declared they were implementing the Lean Construction and one that declared it was not. All the researchers applying the form were trained in this task, supported by the theoretical foundation of lean construction, in order to follow best practice in the application of criteria of the form.

Figure 2 shows that the weighted average has the lowest values in relation to the other averages in all participating companies. With the exception of company $\mathrm{F}$, the arithmetic averages presented intermediate values and results of the Fuzzy were the highest in the other companies. 


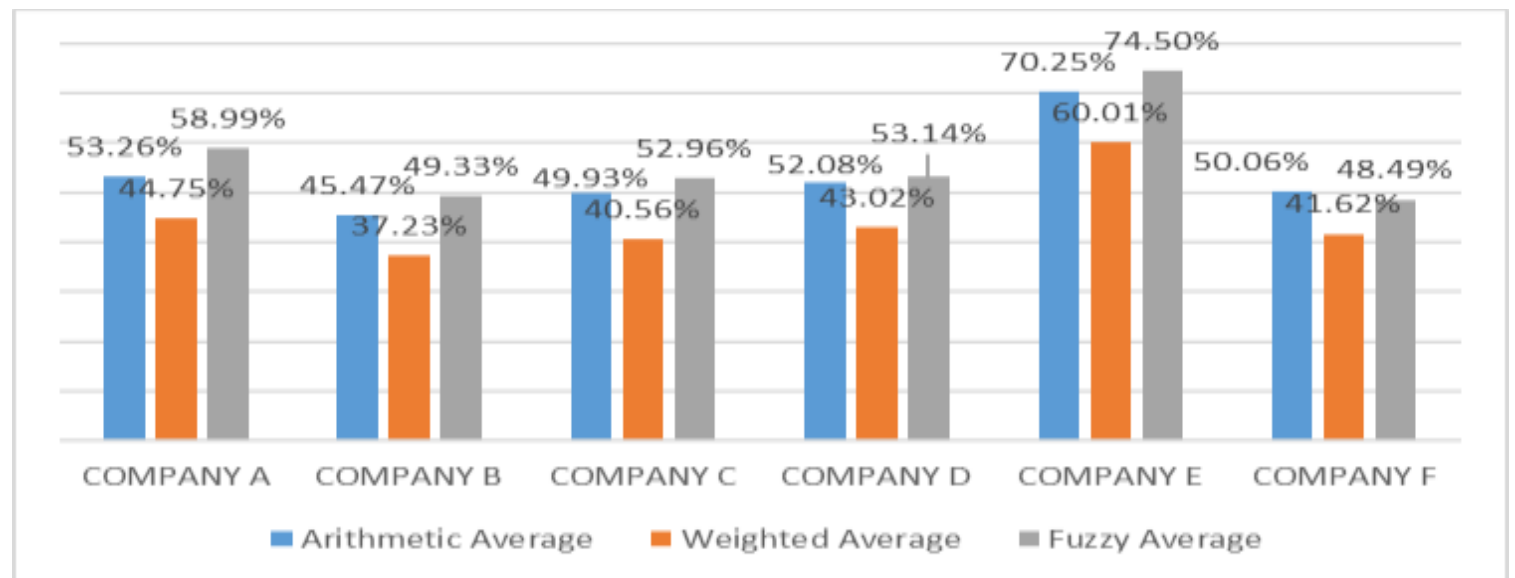

Figure 2: Arithmetic, weighted and Fuzzy averages by company.

\section{Arithmetic AVERAGE}

The following are the arithmetic, weighted and Fuzzy averages of each company with more details as Figures 3 to 8, listed below.

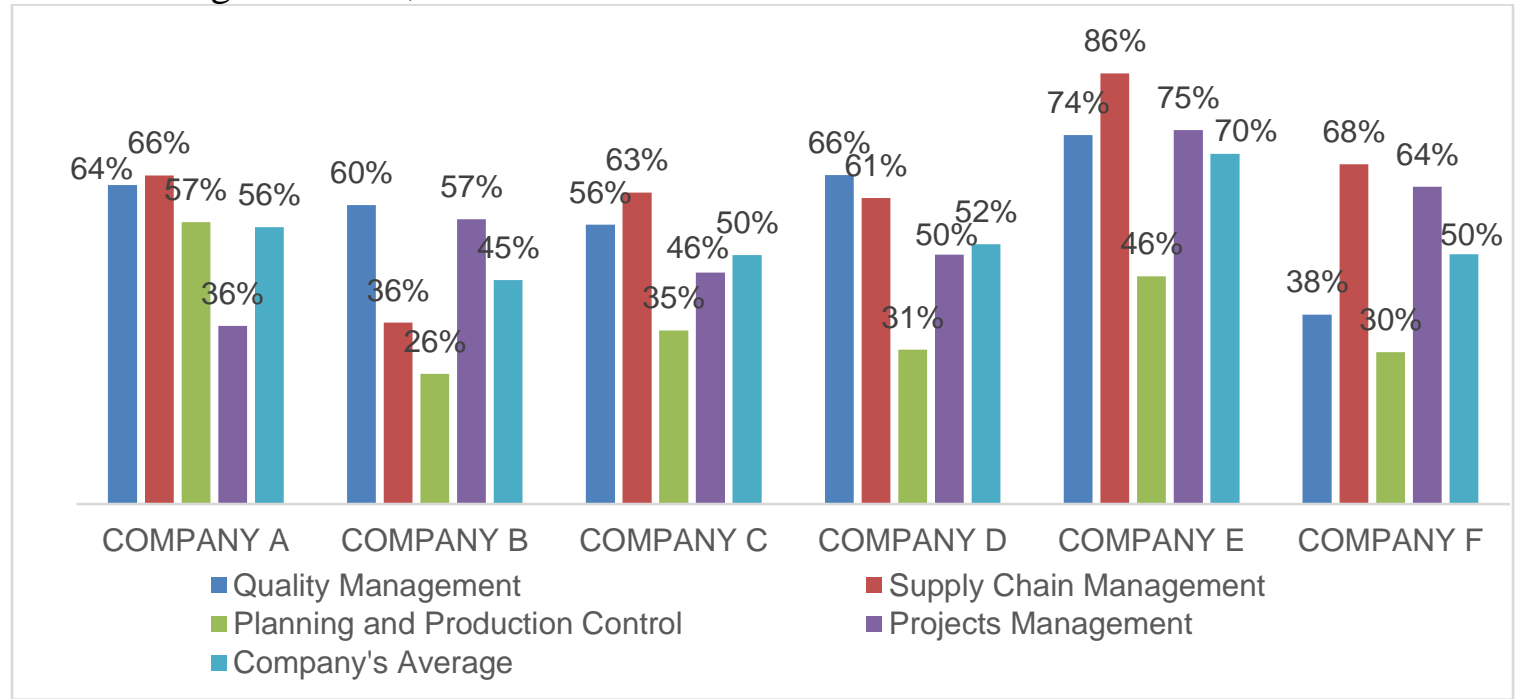

Figure 3: Lean Score by category using the arithmetic averages.

Companies A, B, C, D and F had a Lean Score that ranges from approximately $44 \%$ to $56 \%$, demonstrating that there is a process of implementation of lean construction principles. However, it was noted that there are some important stages missing in the consolidation of this implementation, such as value flow mapping and medium term planning, both of which are part of the production planning and control. 


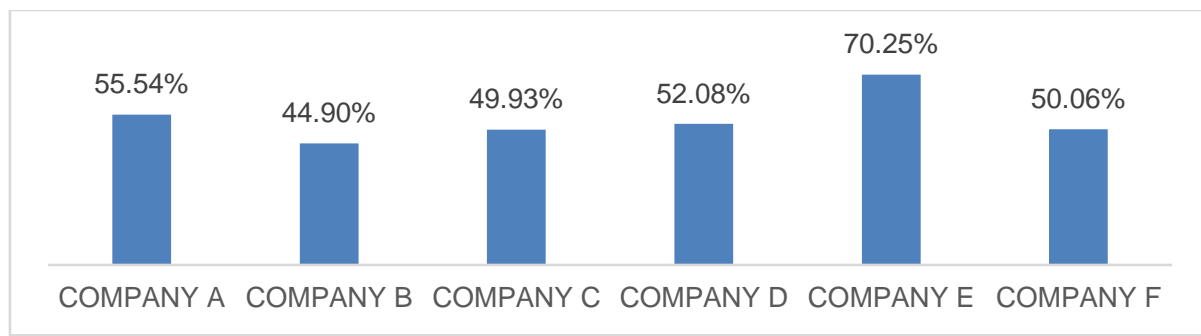

Figure 4: Lean Score by company using arithmetic average.

\section{Weighted Average}

The expert-weighted average had the lowest indices when compared to the other averages in all companies. This result is mainly due to the fact that the specialists classified the vast majority of the items in the initial stage of implementation and maturation, therefore, due to the fact that they had a lower weight in the Lean diagnosis, the averages were lower.

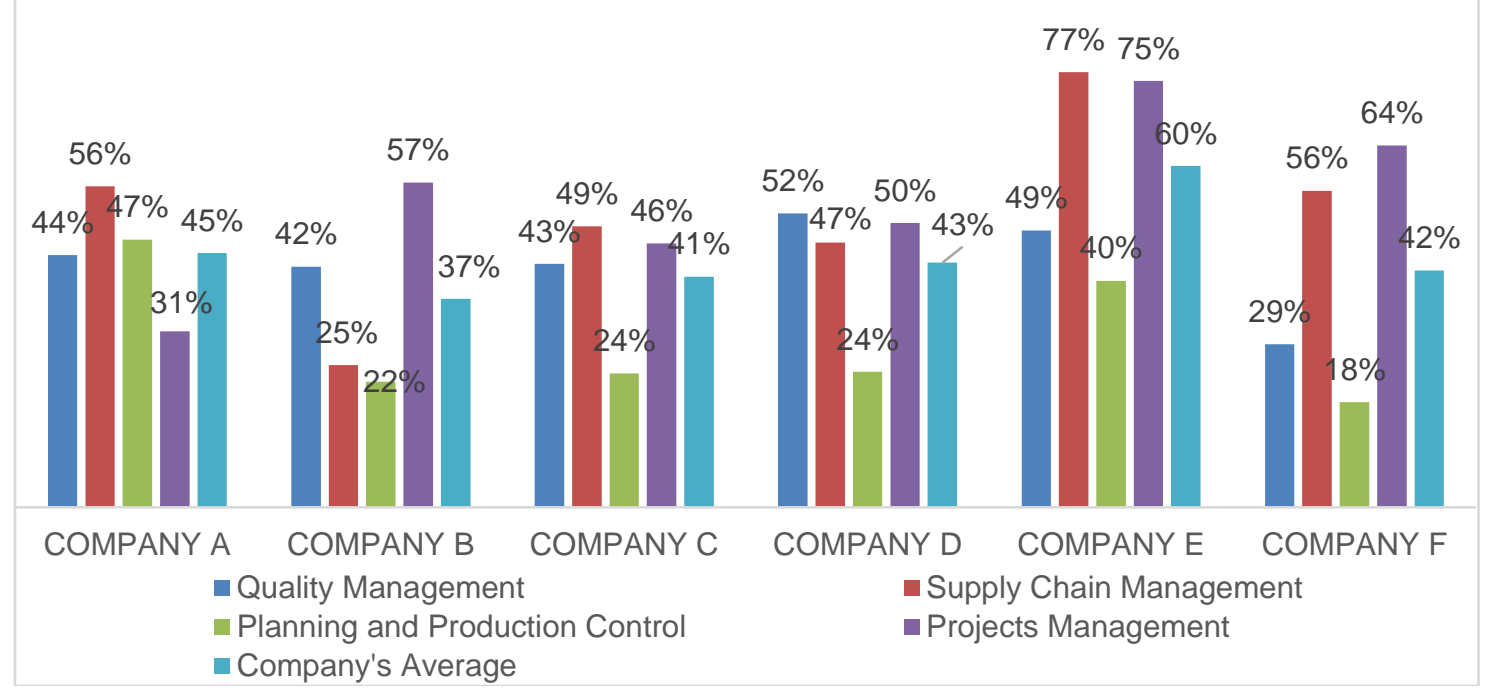

Figure 5: Lean Score by category using weighted average.

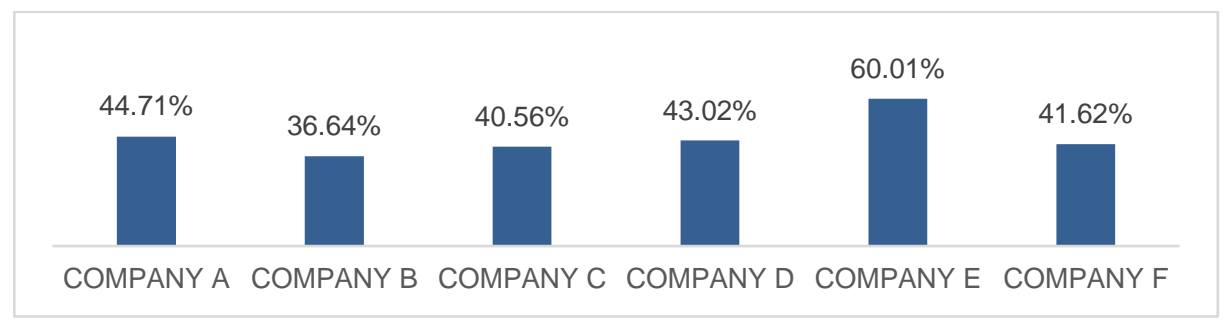

Figure 06: Lean Score per company using weighted average.

\section{FuZzY AVERAGE}

With the exception of company E, which presented a high degree of implementation, all the results were similar (Figure 07). These values close to $50 \%$ characterize an average degree of implementation, and are explained by two factors. First, the implementation stage considered for all companies was zero, i.e. the companies were just beginning the implementation process and the evaluation was less demanding, with some items not 
applied. The second reason is the good performance of most companies in the categories of quality management and supply chain management. This was made possible by the maturation of the implementation of the QMS, and the well-coordinated supply management system.

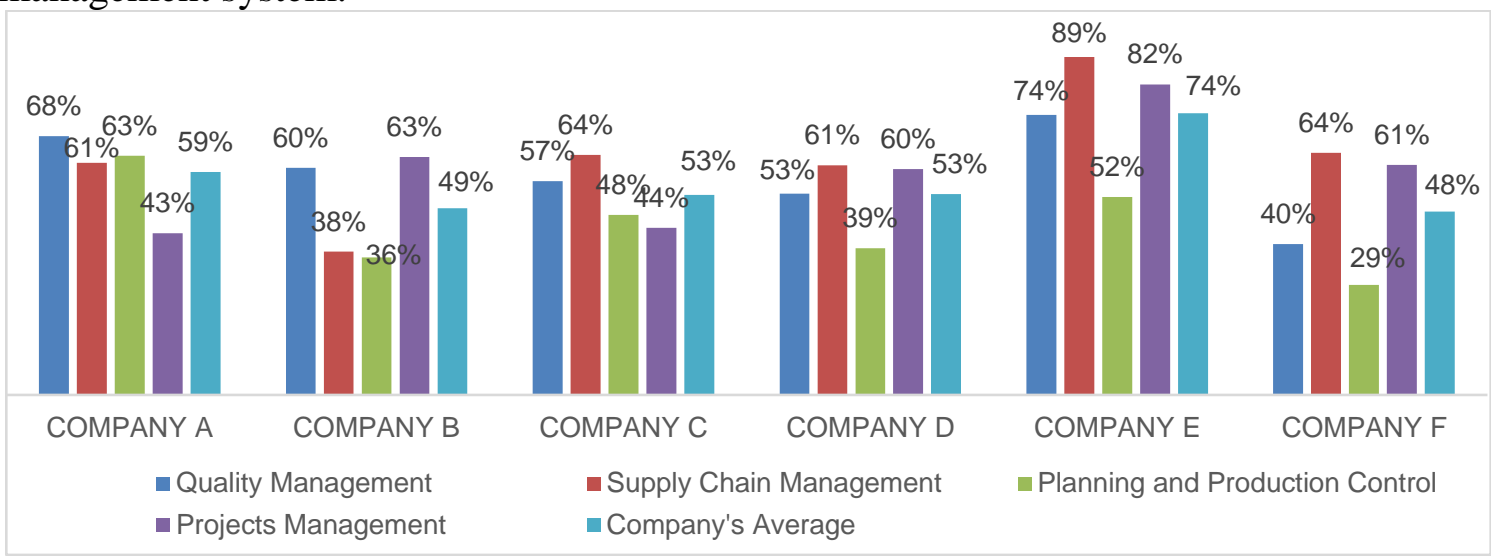

Figure 07: Lean Score by category using Fuzzy averages.

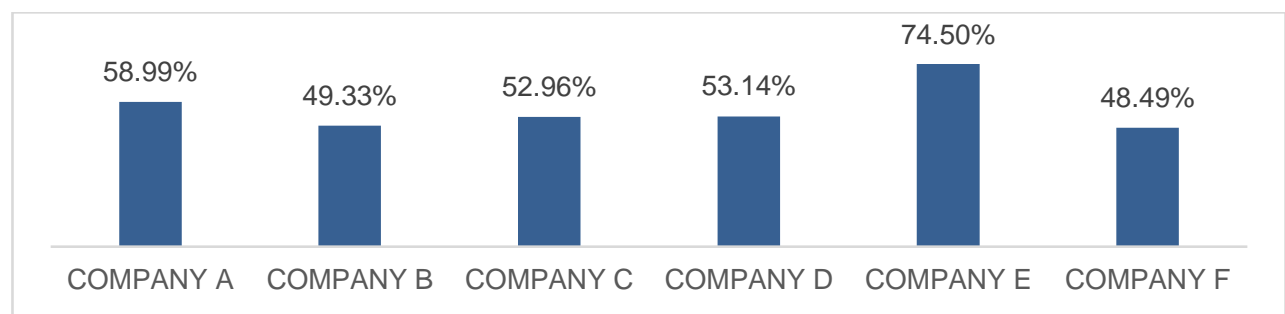

Figure 08: Lean Score per company using Fuzzy averages.

A summary of the Lean Score averages of each company is presented in Table 01.

Table 03: Summary of the Lean Score by Company

\begin{tabular}{cccc}
\hline \multicolumn{5}{c}{ LEAN SCORE } \\
\hline COMPANY & Arithmetic average (\%) & Weighted average (\%) & Fuzzy average (\%) \\
\hline Company A & 56 & 45 & 59 \\
\hline Company B & 45 & 37 & 49 \\
\hline Company C & 50 & 41 & 53 \\
\hline Company D & 52 & 43 & 53 \\
\hline Company E & 70 & 60 & 74 \\
\hline Company F & 50 & 42 & 48 \\
\hline Media & 54 & 45 & 56 \\
\hline
\end{tabular}

It can be seen that with exception of company $E$, which presented a high degree of implementation, all the other results were close to 50\%, characterizing an average degree of implementation.

\section{CONCLUSION}

It is concluded that the three types of average used to calculate the degree of implementation of lean construction fulfilled their functions, and had specific advantages. All three results were representative, and there were no significant difference between them. 
Of the three averages analyzed in this study, the arithmetic average is the simplest one, and the easiest to interpret. However, it does not present the necessary statistical analysis, except for the judgement of the evaluator on attributing a certain score to each criteria established. The influence of extreme values is another factor that could influence the results, as it does not properly represent the set of values.

The weighted average attributed by specialists enables the opinions of third parties to be considered in the results. It is possible to distinguish the relative importance of a particular item within a set of values. In this case, the Lean Score was also influenced by the time of implementation of the practice.

The averages calculated using the Fuzzy Inference System enables various variables to be considered, such as: importance, complexity, time and stage of implementation. This analysis helps to minimize the influence of the evaluator's judgment, and present more precise Lean diagnosis.

Therefore it is not possible to establish a direct comparison between the three types of average, since each takes into account different amounts of variables in their analysis. The arithmetic average depends only on itself, the weighted average depends on two variables - the average and the weighting factor of the specialists - and the fuzzy average is influenced by five variables: importance of the item, importance of the criteria, complexity of the practice, time of implementation of the practice, and time of implementation of lean construction. Thus, each average has different calculation methods, and there are advantages and disadvantages inherent to each.

Regarding the degree of lean implementation of companies in Goiânia, although there is interest in applying the principles of lean thinking, there is no articulated commitment to implementing specific practices. The companies are interested in becoming "leaner", but they lack the knowledge of lean construction, and the fundamental tools that should be used. They apply procedures that they believe to be "good practices", but they do not have the necessary know-how and scientific theoretical knowledge to maintain them effectively in a way that is economically viable. Moreover, there is no kind of certification or benefit for being lean, which in some companies, leads to a lack of interest in implementing these practices. One limitation of this study is the non-existence of benchmarking in the State of Goiás that could be used as a basis for the process of implementation of lean construction. One of the companies obtained a result of more than $70 \%$ in the arithmetic and Fuzzy averages. This represents good performance in lean implementation (by LCAT). However, it cannot be affirmed whether this company used specific processes and tools.

A suggestion for future studies is to compare the levels of implementation and theoretical knowledge of the philosophy with other Brazilian cities, in order to increase the database and the benchmarking between these companies. The results obtained for the construction industry could also be compared with those obtained for other industries, such as the automobile industry, seeking to understand how both work, and how the practices may be related, and bringing benefits for both sectors.

\section{REFERENCES}

CAMARGO FILHO, C. A. B. LCAT: Ferramenta de Avaliação da Implementação da Construção Enxuta. 2017. 99 f. Monografia (Exame de Qualificação) - Programa de 
Pós Graduação em Geotecnia, Estruturas e Construção Civil, Universidade Federal de Goiás, Goiás, 2017.

Carvalho, B. S. "Proposta de uma ferramenta de análise e avaliação das construtoras em relação ao uso da construção enxuta." 2008. 141 f. Dissertation (Master's degree in Civil Engineering) - Curso de Pós-graduação em Construção Civil, Universidade Federal do Paraná, 2008.

Etges, B. M. B. S. "Protocolo de auditoria do uso de práticas da construção enxuta". 2012. 85 f. Dissertação (Mestrado em Engenharia de Produção) - Programa de Pós-graduação em Engenharia de Produção, Universidade Federal do Rio Grande do Sul, 2012.

Etges, B. M. B. S.; Saurin, T. A.; Bulhões, I. R. "A Protocol for Assessing the Use of Lean Construction Practices". In: 21th Annual Conference of the International Group for Lean Construction, 2013, Fortaleza, Brazil. Proceedings... Fortaleza, Brazil. 2013. Disponível em: < http://iglc.net/Papers/Details/896>. Accessed on: 24 Apr. 2017.

FGV/IBRE - Instituto Brasileiro De Economia. Banco de dados: "Sondagem da Construção - Índice de Confiança da Construção". Available at: <http://portalibre.fgv.br/main.jsp?lumChannelId=402880811D8E34B9011D92E5C72 6666F>. Accessed on: 20 Abr. 2017.

MIRON L., TALEBI S., KOSKELA L., e TEZEL A. Evaluation of Continuous Improvement Programmes. In: 24TH ANNUAL CONFERENCE OF THE INTERNATIONAL GROUP FOR LEAN CONSTRUCTION, 2016, Boston, USA. Proceedings... Boston, USA. 2016. Available at: < http://iglc.net/Papers/Details/1287 >. Accessed on: 13 May. 2017.

Salem, O.; Solomon, J.; Genaidy, A.; Minkarah, I. "Lean Construction: From Theory to Implementation". Journal of Management in Engineering, v. 22, n. 4, p. 168-175, 2006.

Silva, R. C. M. "Lógica Fuzzy aplicada à análise de empresas de construção civil segundo os princípios da construção enxuta". 2011. Monografia (Graduação em Engenharia Civil) - Curso de graduação em Engenharia Civil, Universidade Federal de Goiás, 2011.

Silva, R. S. M.; Amaral, T. G.; Silva, F. M. A. "Fuzzy logic applied to Lean construction - An implementation in building companies". Journal of Civil Engineering and Architecture Research. v. 1, n. 1, p. 37-44, 2014.

Susilawati, A.; Tan, J.; Bell, D.; Sarwar, M. "Fuzzy logic based method to measure degree of Lean activity in manufacturing industry. Journal of Manufacturing Systems", United Kingdom, 2014. 
Amaral, T.G., Oka, L. G., Camargo Filho, C.A.B, and Neto, J. P. B

986

Proceedings IGLC - 27, July 2019, Dublin, Ireland 